\title{
Outcome of unstable fractures of the distal end of the radius treated with external fixator
}

\section{Gupta $\mathrm{HK}^{1}$, Shrestha $\mathrm{R}^{1}$, Shrestha $\mathrm{SK}^{1}$}

${ }^{1}$ Lecturer, Department of Orthopedics, College of Medical Sciences and Teaching Hospital, Bharatpur, Chitwan,Nepal

\section{ABSTRACT \\ BACK GROUND AND OBJECTIVES}

Fracture of the distal radius is the most common fracture treated by the orthopedic surgeons. Although there are several treatment options available today, the aim always remains to restore the anatomy and bring back the function to near normal condition. In this prospective study we intend to evaluate the functional and radiological outcome of the unstable fracture of the distal radius when treated with external fixator.

\section{MATERIALS AND METHODS}

In this hospital based, Prospective study conducted in department of Orthopedics, College of Medical Sciences Teaching Hospital, Bharatpur, Chitwan, during the period from January 2011 to September 2012, 54 patients, (33 male and 21 female) with unstable fracture of the distal end of radius were included in the study. All the patients were treated with external fixator and followed for a period of 12 weeks.

\section{RESULT}

Among 54 patients, 52 were followed up for 12 weeks and two patients were lost to follow up after six weeks. The final result was assessed in detail on the basis of Modification, by Sarmiento et al., of the Demerit Point system of Gartland and Werley at the end of 12 weeks. The result was excellent in 25 cases, good in 19 cases and fair in eight cases. There were no poor results in this series.

\section{CONCLUSION}

External fixator is not only easy to use, allows re-reduction, has lower rate of complications and can be stiff enough to maintain the alignment but it is also a cost effective, patient compliant method which causes lesser morbidity to the patient as compared to the other options available.

\section{Keywords: External fixator, Fracture distal radius, Demerit point system}

Correspondence: Dr. Hemant Kumar Gupta

Email: hmntkg@yahoo.com 


\section{INTRODUCTION}

The fracture of distal radius constitutes 15\% all of the fractures in adult ${ }^{1}$. Fractures of the distal aspect of the radius with intra- articular involvement and comminution continue to pose therapeutic challenge. ${ }^{\mathrm{i}} \mathrm{A}$ key method of surgical fixation of such fractures is external fixation. External skeletal fixation has been popular for the treatment of displaced, unstable fractures of the distal part of the radius because it combines a minimally invasive procedure with reduction by ligamentotaxis. ${ }^{\text {ii }}$

Anderson and O'Neil (1944) were the first to introduce the use of external fixation in the treatment of these fractures. ${ }^{\text {iii }}$ The importance of alignment correction, preservation of normal radial length and reconstruction of congruity of both the radio- carpal and radioulnar joints has been emphasized time and time again. Restoration of congruity of the articular surface is the most critical factor for a good functional result. Restoration of radial length, radial tilt angle, and volar tilt angle is also important. Failure to achieve and maintain nearly anatomic restoration can lead to degenerative arthritis, distal radio-ulnar and mid- carpal instability, and ulnar impaction syndrome, with resultant pain, decreased motion and strength.

The fixator chosen should be easy to use, allow re-reduction, low rate of complications and be stiff enough to maintain the alignment. The purpose of this study was to evaluate OUTCOME OF UNSTABLE FRACTURES OF THE DISTAL END OF THE RADIUS TREATED WITH EXTERNAL FIXATOR.

\section{METHODS}

This interventional and observational study was conducted in College of Medical Sciences Teaching Hospital Bharatpur,
Chitwan from January 2011 to September 2012. Fifty- four patients with fracture of distal radius satisfying the following criteria were treated with external fixator and included in the study:

1. Dorsal angulation of more than 20 degrees

2. Loss of radial length of more than 10 millimeters

3. Intra articular extension

4. Severe dorsal metaphyseal comminution

Patients were operated under brachial plexus block and general anesthesia when brachial block failed. Tourniquet was not used for the surgery. Under fluoroscopic guidance closed reduction was done. Two schanz pins on each sides of the fracture were applied and connected with a pair of AO rods (Fig- 1,2). The external fixators were removed at $6^{\text {th }}$ week (Fig 3) and using Modification, by Sarmiento et al, ${ }^{\text {iv }}$ of the Demerit Point system of Gartland and Werley ${ }^{\mathrm{v}}$, subjective and objective evaluation of functional status and radiographic data were evaluated at $12^{\text {th }}$ week (Fig- 4,5 6,7,8)

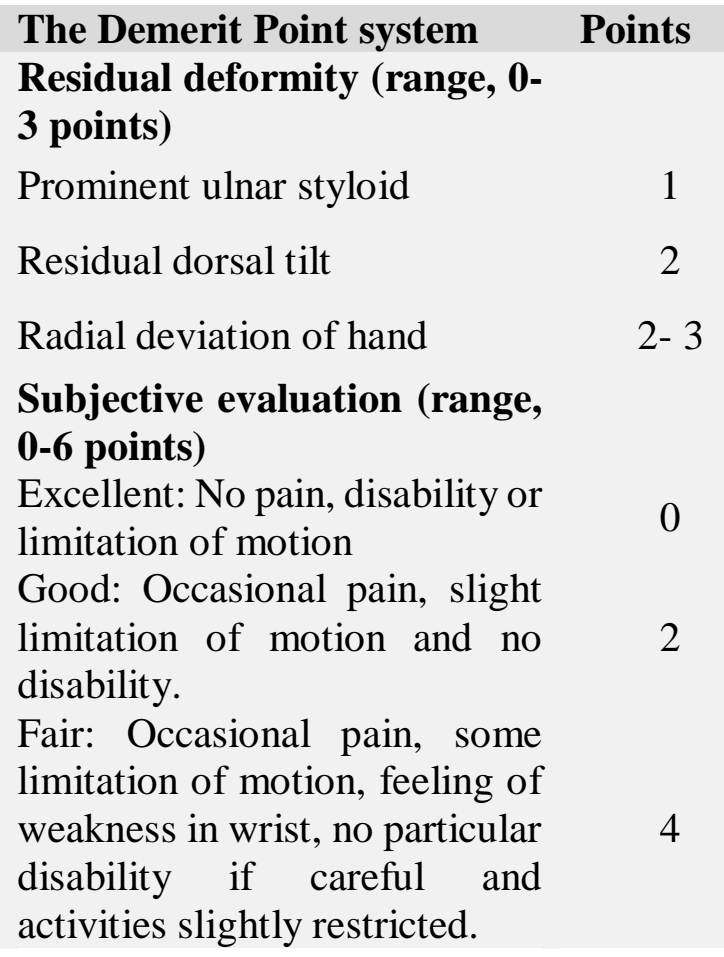


Gupta H.K. et al., Outcome of unstable fractures of the distal..

Poor: Pain, limitation of motion, disability and

activities more or less markedly restricted. 6

\section{Objective evaluation (range, $0-5$ points)}

Loss of dorsiflexion $\left(<45^{\circ}\right)$

Loss of ulnar deviation $\left(<15^{\circ}\right)$

Loss of supination $\left(<50^{\circ}\right) \quad 2$

Loss of palmar flexion $\left(<30^{\circ}\right) \quad 1$

Loss of Radial deviation $\left(<15^{\circ}\right) \quad 1$

Loss of circumduction 1

Pain in distal radio - ulnar joint $\quad 1$

Grip strength (60\% or less of opposite side) $\quad 1$

Loss of pronation $\left(<50^{\circ}\right) \quad 2$

\section{Complications (range 0 to 5 )}

Osteoarthrotic change

Minimum

Minimum with pain

Moderate

Moderate with pain

Severe

Severe with pain

Nerve complications (Median)

Poor Finger function due to cast

\section{End results (points range)}

Excellent

Good

Fair

Poor

\section{RESULTS}

Among 54 patients, 52 were followed up for 12 weeks and two patients were lost to follow up after 6 weeks. In the present study mean age was $34.94 \pm 9.06$ and maximum incidence occurred between 31 to 40 years (38.9\%). There were 33 males (61.1\%) and 21 females (38.9\%) and the female to male ratio was $1: 1.57$. The time from injury to operation averaged $1.61 \pm 1.25$ days and ranged from zero to eight days.

In our study the major cause of fracture were motor vehicle accidents (57.4\%) and fall from a height (27.8\%). Out of 54 distal radius fractures, 24 (44.4\%) were of the right side and $30(55.6 \%)$ were of the left side. The most common type of fracture according to AO/ASIF classification was Type C 1 (50\%) which was followed by Type C 2 (25.9\%) and Type C 3 $(18.5 \%)$.

At the end of 12 weeks in antero-posterior radiograph of distal radius radial inclination was found to be in the range of 23 to 18 degree in 43 cases, 17 to 13 degree in 7 cases and 12 to 10 degrees in 2 cases. Radial height was equal to or less than $6 \mathrm{~mm}$ in only six $(11.5 \%)$ cases. Only one patient had ulnar variance of more than $2 \mathrm{~mm}$ while the remaining 51 patients had it in the range of -2 to $2 \mathrm{~mm}$. Articular step-off of more than $2 \mathrm{~mm}$ was present in only two $(3.8 \%)$ cases. In the lateral radiograph, tilt of the distal radius was measured which was volar tilt, upto 11 degree in 37 (71.2\%) cases while dorsal tilt was found in $15(28.8 \%)$ cases.

Three $(5.6 \%)$ patients developed pin tract infection, four $(7.4 \%)$ patients complained of puckering of the skin at the site of insertion of schanz pins, three $(5.6 \%)$ patients felt paraesthesia in the dorsum of thumb and index finger and one (1.9\%) patient had stiffness of the ipsilateral elbow. 
Journal of College of Medical Sciences-Nepal, 2014, Vol-10, No-2 The final result was assessed in detail on the basis of Modification, by Sarmiento et al., of the Demerit Point system of Gartland and Werley at the end of 12 weeks. The result was excellent in $25(48.1 \%)$ cases, good in $19(36.5 \%)$ cases and fair in eight $(15.4 \%)$ case. There were no poor results in this series. Twenty-one out of 31 males had excellent result while only five out of 21 females had excellent result. Out of $25 \mathrm{C} 1 \mathrm{AO}$ type fractures 12 had excellent results while six out of 10 C3 AO type fractures had fair results.

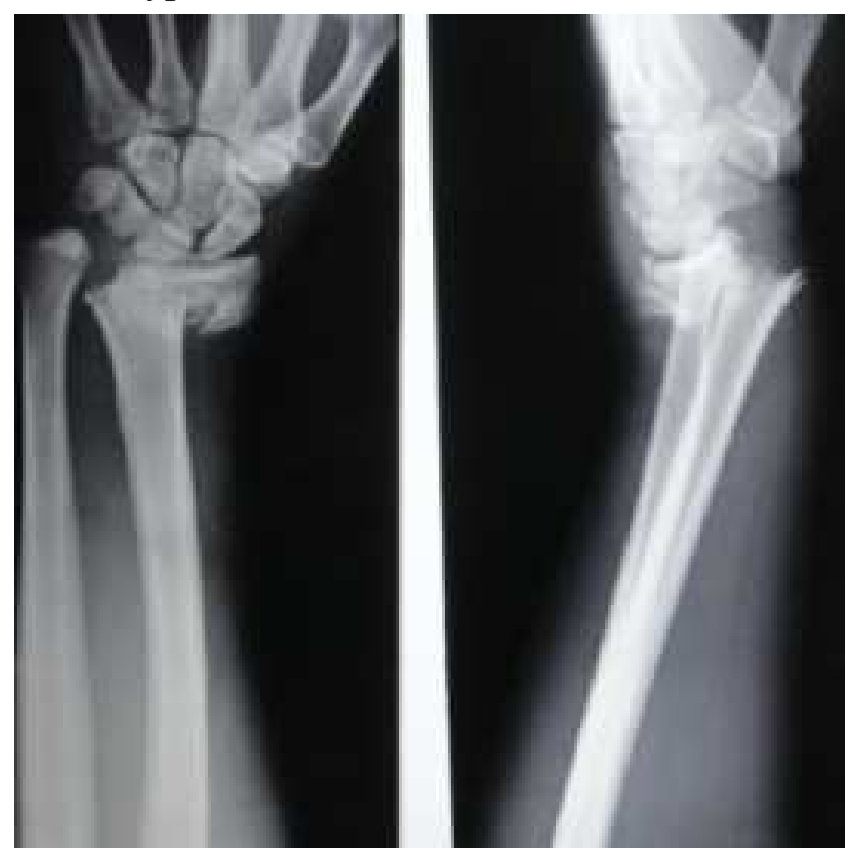

Fig. 1: Pre Op

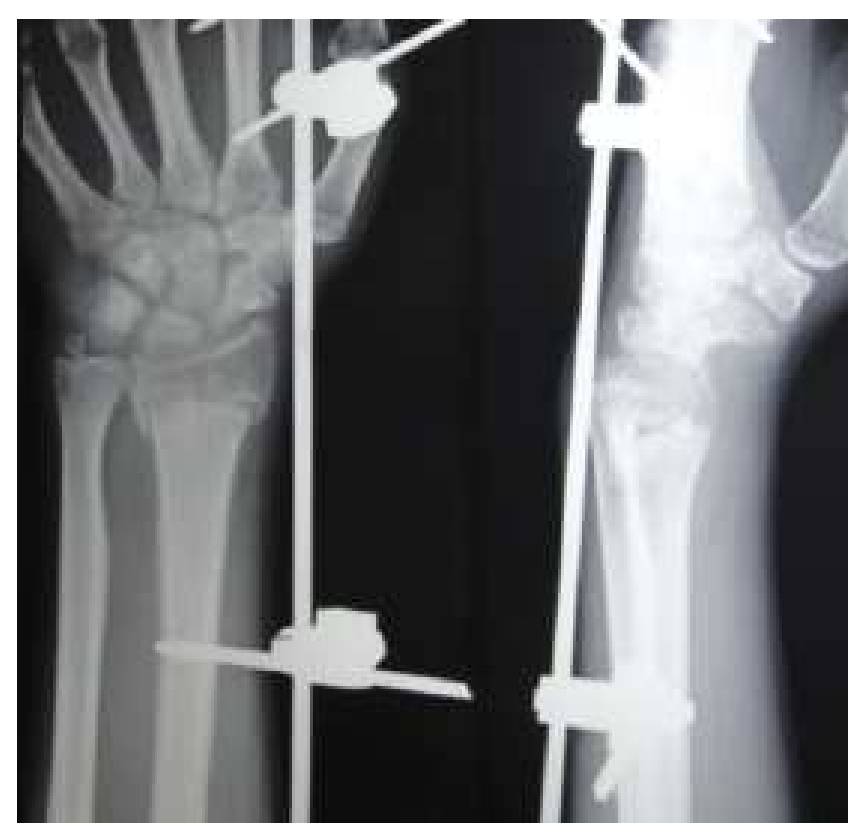

Fig. 2: Post Op

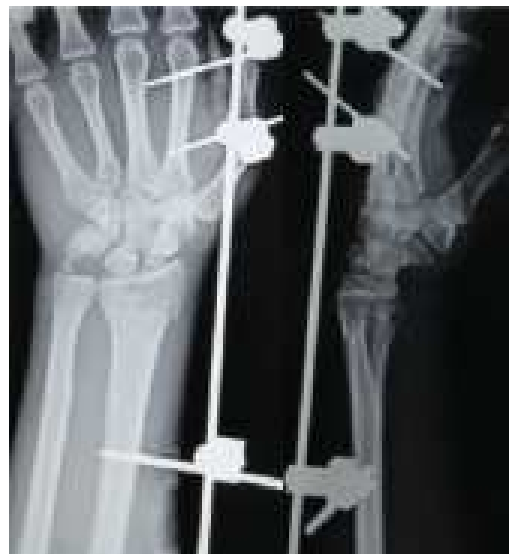

Fig. 3: at 6 Weeks

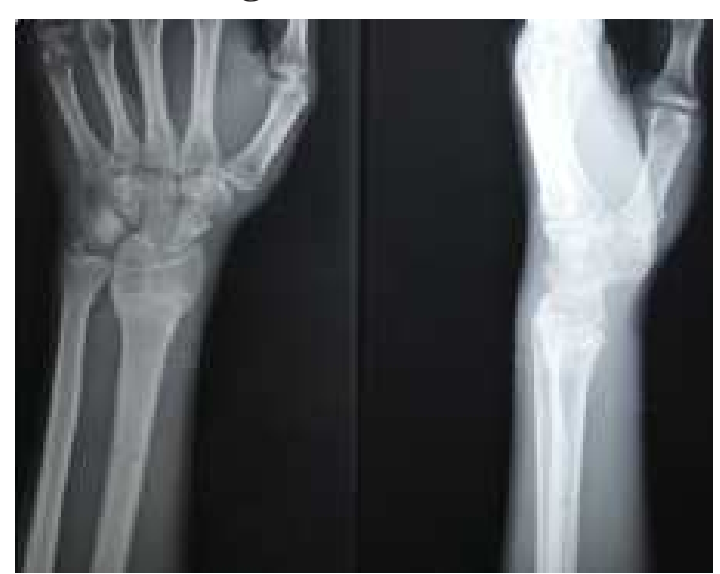

Fig. 4: at 12 Weeks

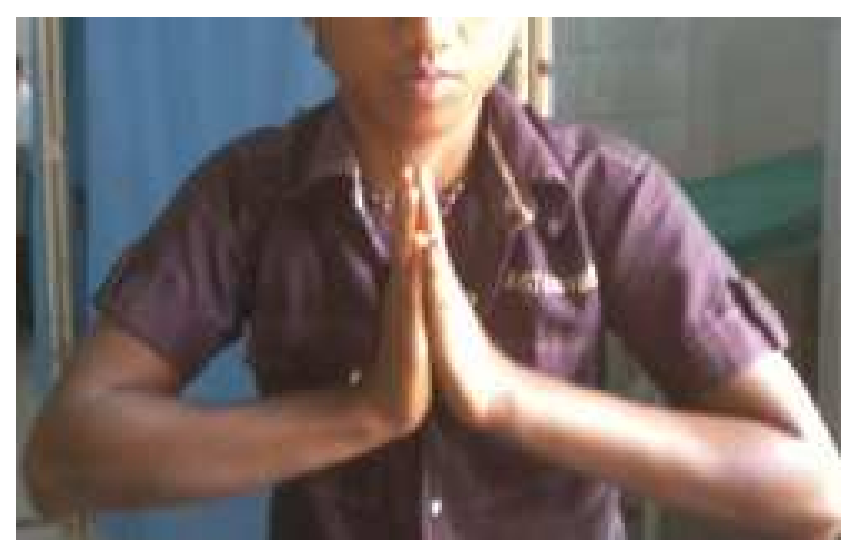

Fig. 5: Dorsiflexion

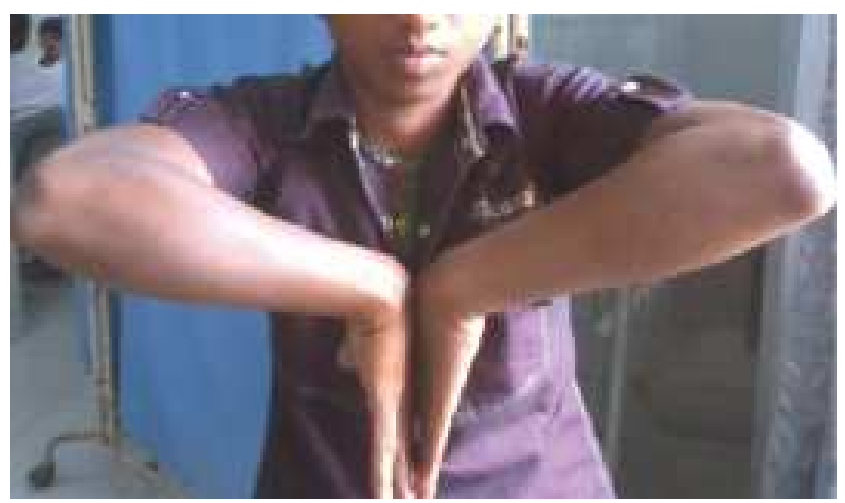

Fig. 6: Palmar Flexion 


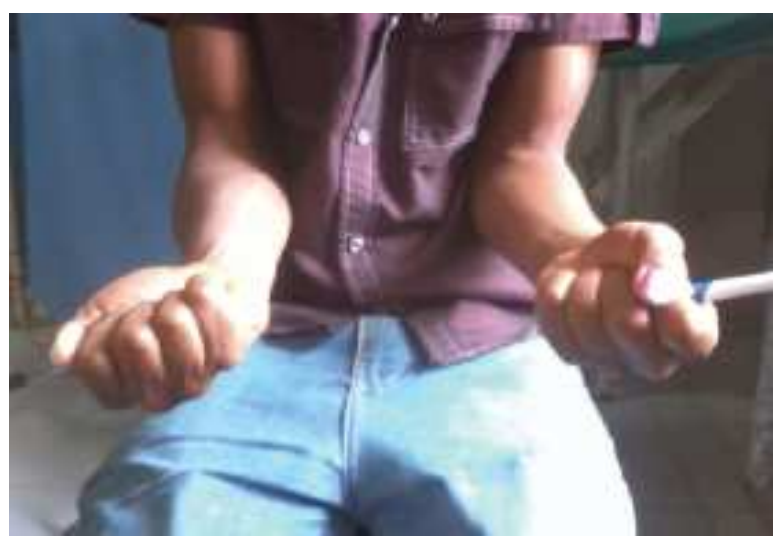

Fig. 7: Supination

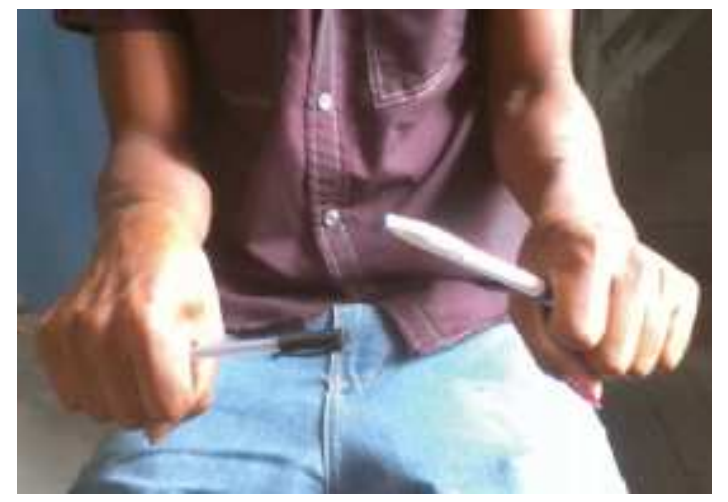

Fig. 8: Pronation

\section{DISCUSSION}

A good number of surgeons advocate external fixator as it is inexpensive, patient compliant, causes less morbidity and puts less burden on the patient in the sense that it decreases the hospital stay and also its removal can be done in an out-patient basis without the need of anesthesia.

Closed manipulation and plaster cast, pins and plaster, percutaneous pinning and external fixation with or without bone graft are the commonly used methods of treatment of distal radius fracture. The advent of external fixator has changed the face of the management of such fractures. The ability of external fixators to maintain radial inclination, radial height and volar tilt without opening the fracture site has made it a popular choice among the surgeons worldwide.

Various studies have shown that it not only gives a good functional result and patient satisfaction but also allows near normal anatomic restoration. ${ }^{6,7,8,9}$ As evaluated with Modification, by Sarmiento et al., of the Demerit Point system of Gartland and Werley, Sommerkamp et al. ${ }^{10}$ concluded that $92 \%$ of the results at one year were excellent or good in patients treated with static external fixator while they were excellent in $90 \%$, good in $6.66 \%$ and poor in $3.33 \%$ in a study conducted by Edwards. ${ }^{4}$ Huge number of favorable result in our study is mainly attributed to meticulous preoperative assessment, appropriate technique of fixation and continuous patient education regarding pin site care and physical therapy.

All the cases of pin site infections were eradicated with regular pin site dressing with hydrogen peroxide and a course of antibiotics without any sequelae. Paraesthesias in all three patients gradually improved after some weeks without any specific treatment. The patient who complained of stiffness of elbow also regained near normal range of motion by the end of 12 weeks with appropriate physiotherapy. The cause of stiffness in that case was attributed to immobilization of the ipsilateral elbow in an above elbow posterior slab following its posterior dislocation. There were no complains of reflex sympathetic dystrophy, rupture of extensor pollicis tendon or pin loosening.

In a study done by Edwards, complications included temporary drainage from pin tract in $26.66 \%$ patients. Infections were controlled by antibiotics or removal of fixators. None of the patients had loss of fixation or breakage of pins. There were no instances of reflex sympathetic dystrophy or nerve injuries. $3.33 \%$ of patients had some puckering from an adherent scar and another $3.33 \%$ had slight spreading of the scars. ${ }^{4}$

Jakim et al. reported superficial pin tract sepsis in 5.2\% cases which is consistent with our pin site infection rate of $5.6 \%$. There were $2.6 \%$ cases of pin loosening $2 \%$ patients developed post-traumatic arthritis. ${ }^{11}$ 
Although we have found external fixator to be an excellent method of treating unstable distal radius fracture in our study, it definitely needs a long term follow up to evaluate any improvement or deterioration in the outcome. The high rate of excellent and good results in this series has certainly made its mark in the wide range of treatment options that we have today.

\section{Conclusion}

In this mode of treatment, there is minimal blood loss and minimal risk of infection. There is a minimal risk of injury to the neurovascular structures.

It is a cost effective procedure, easy to use, allows re-reduction, and is stiff enough to maintain the alignment.The operating time is very less as compared to the other methods. It causes less morbidity to the patient and requires a minimal period of hospital stay The implants can be removed without anesthesia as an out-patient procedure..

\section{References}

1. Mehboob I, Anjum MP. Fixation of extra articular distal radius fractures with non bridging external fixator. Nepal Med coll J. 2008;10:115-7.

2. Werber KD, Raeder F, Brauer RB, et al. External Fixation of Distal Radial Fractures: Four Compared with Five Pins: A Randomized Prospective Study. J Bone Joint Surg Am. 2003;85:660-6.

3. Edwards GS. Intra-articular fractures of the distal part of the radius treated with the small AO external fixator. J Bone Joint Surg Am. 1991;73:1241-50.
4. Sarmiento A, Pratt GW, Berry NC, et al. Colle's fractures. Functional bracing in supination. J Bone and Joint Surg. 1975;57:311-17.

5. Gartland JJ, Werley CW. Evaluation of healed Colle's fractures. J Bone and Joint Surg. 1951;33:895-907.

6. Haus BM, Jupiter JB. Intra-articular fractures of the distal end of the radius in young adults: Reexamined as evidence based and outcome medicine. J Bone Joint Surg Am.2009;91:2984-91.

7. Knirk J, Jupiter JB. Intra-articular fractures of the distal end of the radius in young adults. J Bone Joint Surg Am. 1986;68:647-59.

8. Boparai R, Boparai RS, Kapila R, et al. Role of ligamentotaxis in management of comminuted intra/ juxta articular fractures. Indian J Orthop. 2006;40:185-7.

9. Clyburn TA. Dynamic external fixation for comminuted intra-articular fractures of the distal end of the radius. J Bone Joint Surg Am. 1987;69:248-54.

10. Sommerkamp TG, Seeman M, Silliman J, et al. Dynamic external fixation of unstable fractures of the distal part of the fixation radius. A prospective, randomized comparison with static external. J Bone Joint Surg Am. 1994;76:1149-61.

11. Jakim I, Pieterse HS, Sweet MBE. External fixation for intra-articular fractures of the distal radius. $\mathrm{J}$ Bone Joint Surg (Br). 1991;73:302-6. 